\title{
LA IGLESIA Y LA REPRESIÓN EN LA GUERRA CIVIL ESPAÑOLA
}

\section{HILARI RAGUER SUÑR}

Abadía de Montserrat, Barcelona

hraguer@gmail.com

\section{Resumen:}

La terrible persecución religiosa en la zona republicana tuvo un comprensible eco en Roma. Pero la actitud del Vaticano fue muy reticente, porque al principio el resultado era incierto y por temor al influjo fascista y sobre todo nazi. La primera toma de posición pública fue el discurso de Pío XI en Castelgandolfo, el 14 de septiembre de 1936. El Vaticano tardó casi dos años en reconocer plenamente a Franco, y lo hizo por realismo, porque ganaba. Los obispos españoles, aunque en 1936 deseaban un golpe militar, no habían entrado en la conspiración. Se adhirieron "a posteriori" a ella. Su toma de posición más importante fue la carta colectiva al episcopado mundial, de 1 de julio de 1937. Se opusieron a todos los intentos de mediación internacional y paz negociada y negaron la represión franquista. La Iglesia española ha de pedir perdón.

\section{Palabras clave:}

Guerra Civil - Represión - Iglesia - Obispos

\begin{abstract}
:
The terrible religious persecution in the republican area had an understandable echo in Rome. But, at the beginning, the Vatican's attitude was very reticent because the result was uncertain and also for the fear to the Fascist' influence and, mainly, the Nazism. The first public taking of a post was the speech of Pope Pius XII in Castelgandolfo on 14th September 1936. The Vatican took around two years before recognising thoroughly General Franco, and they did it for being realists, he was winning. The Spanish bishops, despite they had wished the military coup, they hadn't joined to the conspiracy. They supported it a posteriori. Their most important taking of a post was a collective letter to the worldwide episcopate, on 1st July 1937. They disagreed with any of the efforts for an international mediation and a negotiated peace. They rejected to recognize the Franco's repression. The Spanish Church should ask for forgiveness.
\end{abstract}

\section{Keywords:}

Civil War - Repression - Church - Bishops 


\title{
LA IGLESIA Y LA REPRESIÓN EN LA GUERRA CIVIL ESPAÑOLA
}

\author{
HILARI RAGUER SUÑER \\ Abadía de Montserrat, Barcelona \\ hraguer@gmail.com
}

\section{Introducción}

\section{La niña que no podía llorar}

Permítaseme empezar mi exposición evocando un recuerdo de la guerra civil. Estaba yo a punto de cumplir ocho años cuando empezó. Fue en uno de los primeros bombardeos de Barcelona. En la escuela, cuando sonaban las sirenas de alarma, nos hacían alinear arrimados a una pared maestra. Había una niña que estaba espantada, con los ojos muy abiertos, y con otro niño nos burlábamos de ella diciendo: "Ésta tiene miedo" (así disimulábamos el miedo que nosotros mismos teníamos). La maestra se dio cuenta y abrazó a la niña mientras le decía suavemente: "llora, llora", hasta que la niña estalló violentamente en un llanto como histérico. Yo no lo entendí entonces. Pensaba que mi compañero y yo sólo habíamos querido burlarnos un poco de la niña, pero que no queríamos hacerla llorar, pero siendo ya mayor me he acordado muchas veces de lo que hizo aquella maestra y de cómo seguramente la salvó de quedar traumatizada para siempre. Y cuando los que durante cuarenta años nos estuvieron machacando con su falsa versión de la historia, no dejaron hablar a los testigos y nos negaron el acceso a los archivos nos dicen ahora que no hay que hurgar en las heridas de la guerra civil, me parece que aquella condiscípula de mi infancia es paradigma de todo un pueblo que todavía no ha estallado en llanto, que necesita hacerlo y que apenas en estos últimos años está empezando a hacerlo. ¡Que no traten de impedírselo!

\section{La rebelión de los nietos}

En nuestros días se ha producido lo que se ha llamado "la rebelión de los nietos". ${ }^{1}$ Es un fenómeno que se ha constatado a nivel internacional. En un congreso sobre la memoria histórica, celebrado en Barcelona hace unos años, conferenciantes de España, Chile, Argentina, Alemania (holocausto) y Rusia (represión estalinista) coincidieron en esto: la viuda no habla a los hijos de cómo murió su marido, los hijos no preguntan; son los nietos los que, superada la dictadura, exigen que les cuenten el misterio de la muerte de su abuelo. ${ }^{2}$

\section{El Vaticano y la guerra civil}

Al hablar de la Iglesia y la guerra civil, hay que distinguir entre la actitud del Vaticano y la del episcopado español. Lo más importante del presente estudio es que el Vaticano no compartió el belicismo de la Iglesia española.

\footnotetext{
${ }^{1}$ Véase Capellà, Margalida, "La rebelión de los nietos", en La Vanguardia, 26 de octubre de 2008.

2 Congreso Internacional Arqueología forense, recuperación de la memoria y lucha contra la impunidad, Universidad Autónoma de Barcelona, enero de 2007.
} 


\section{El Vaticano aceptó la República}

El Vaticano había aceptado la proclamación de la República, en 1931. Incluso Monseñor Tardini decía y repetía, a propósito de la caída de la monarquía, y con ella del privilegio real de presentación de obispos: "Benedetta rivoluzione, porque por primera vez en cinco siglos podremos nombrar libremente obispos en España". ${ }^{3}$ Los cardenales de la Congregación de Asuntos Extraordinarios, en su reunión plenaria del 23 de abril de 1931, y con ellos Pacelli y en definitiva el Papa, consideraron el cambio de régimen ilegítimo, porque creían que de unas elecciones municipales no podía resultar un cambio de régimen, pero a la vez creyeron oportuno aceptarlo de facto para poder negociar con el nuevo gobierno y poder defender los derechos e intereses de la Iglesia desde la legalidad y dentro del sistema democrático parlamentario. Secretaría de Estado, a través del nuncio Tedeschini, ordenó a todos los obispos que hicieran actos de acatamiento del nuevo régimen, y así lo hicieron todos, con más o menos entusiasmo y algunas reticencias.

\section{El eco de la persecución religiosa}

Los eclesiásticos y gente de derechas que en los primeros meses, que fueron los más sangrientos, lograron escapar, al llegar a Marsella, Génova o Roma actuaron como una poderosa caja de resonancia comparable a la que supusieron los aristócratas franceses escapados del Terror revolucionario y refugiados en los reinos y principados alemanes del otro lado del Rin. Las víctimas de la guillotina en 1792 han suscitado mucha más literatura y hasta cine que las de la represión de la Commune en 1871, aunque éstas fueron varias veces más numerosas. Es un hecho ilógico, pero real, que los cadáveres no abultan igual. El de un obispo, un aristócrata, un empresario o un general abulta más que el de un obrero, un campesino o un pobre diablo. Éstos, por lo demás, en la zona rebelde no tenían escapatoria, porque nadie les facilitaba una embajada para refugiarse o un barco para escapar al extranjero. Se comprende que se creara en Roma un ambiente unilateral. Las Casas Generalicias de las distintas órdenes o congregaciones religiosas se estremecían, con razón, ante las noticias que les llegaban de la suerte de sus correligionarios y presionaban a los órganos de la Curia Vaticana con los que mantenían relación regular. Tal es el telón de fondo de las primeras reacciones de la Santa Sede.

\section{E1 "tercerismo" del Vaticano}

Cuando estalló la guerra civil, el Vaticano no compartió la actitud belicista del episcopado español. Su posición ha de calificarse de "tercerista": ni fascismo ni comunismo, condenando la persecución religiosa pero muy lejos de identificarse con los militares sublevados. Es la toma de posición de Pío XI en su discurso de Castelgandolfo, el 14 de septiembre de 1936, ante un grupo de prófugos españoles, como seguidamente veremos, y también, en marzo de 1937, en la llamada "Pascua de las tres encíclicas": una contra el comunismo, otra contra el nazismo y otra contra la persecución en México. No hubo una encíclica sobre la guerra de España, aunque en la de México es posible que aludiera a España. El gobierno de los rebeldes no fue plenamente reconocido, con intercambio de embajador y nuncio, hasta mayo de 1938, tras casi dos años de guerra. Si, a pesar de la terrible persecución religiosa en la zona republicana, la Santa Sede se resiste a reconocer a Franco, es, primero, porque no está claro quién ganará; segundo, por el temor que le inspira el influjo fascista y sobre todo nazi, ya que Italia y Alemania son los grandes y decisivos aliados de los insurrectos. Si a mediados de 1938 la Santa Sede reconoce plenamente a

3 Cf. Casula, Carlo Felice, Domenico Tardini (1886-1961). L'azione della Santa Seden nella crisi fra le due guerre, Roma, Studium, 1988. 
Franco es, simplemente, por realismo ante la suerte de las armas. Aparentemente las relaciones entre Burgos y el Vaticano son idílicas, pero la documentación reservada revela graves conflictos, que en algún momento llegan al borde de la ruptura de relaciones. Por lo demás, el Vaticano mantuvo abierta (aunque inactiva) la Nunciatura de Madrid durante toda la guerra.

\section{E1 discurso de Castelgandolfo}

Cuando se supo en Roma que Pío XI recibiría en audiencia, en su residencia veraniega de Castelgandolfo, a un numeroso grupo de prófugos españoles y que les dirigiría un discurso, cundió la expectación entre el clero español de Roma. Correspondía presidir el grupo y dirigir el saludo al Papa en nombre de todos al cardenal Vidal y Barraquer, arzobispo de Tarragona, pero era tal la animosidad de la mayoría de los eclesiásticos españoles y políticos de extrema derecha contra él (porque, siguiendo las instrucciones de Secretaría de Estado, había trabajado por la conciliación de la Iglesia con la República) que el Papa le hizo decir que juzgaba más prudente que no asistiera. El 2 de setiembre Vidal y Barraquer escribió a Pacelli aceptando sumisamente, aunque con dolor, aquella exclusión, pero aprovechó la ocasión para exponer su criterio sobre las repercusiones que aquel acto podría tener: el apasionamiento de buena parte de los participantes podía comprometer a los prelados presentes, y a la vez repercutir muy negativamente en la situación de los muchísimos eclesiásticos y católicos seglares que se hallaban aún bajo el peligro revolucionario; no se podía olvidar -añadía el cardenal de Tarragona- que estos perseguidores de la religión son también hermanos nuestros, por lo que sería necesaria "una gran paciencia con todos aquellos que no reflexionan, que están ciegos, que están todos exacerbados y ofuscados por la pasión y el deseo de venganza"; a su juicio, un acto ruidoso de protesta, además de ser ineficaz, constituiría "un mayor obstáculo para que los sacerdotes pudieran entrar de nuevo en España y trabajar por la conversión de quienes, a pesar de su perversión y maldad, no dejan de ser nuestros hermanos"; añadía aún que aquella dolorosa situación de la Iglesia en España no se debía únicamente a los enemigos declarados del catolicismo, sino también a que buena parte de los creyentes, incluso eclesiásticos, saliendo del campo que les era propio, habían fomentado la discordia con fines meramente políticos. ${ }^{4}$

$\mathrm{El}$ influjo de esta carta en el tenor del discurso pontificio es evidente. Por otra parte, seguramente había llegado ya al Vaticano la carta de Gomá a Pacelli del 2 de setiembre comunicando que la Junta de Defensa Nacional de Burgos exigía firmemente, bajo las peores amenazas, la expulsión del obispo de Vitoria Mateo Múgica, acusado de nacionalista vasco.

Asistieron a la audiencia de Castelgandolfo unos quinientos españoles, la mayoría sacerdotes y religiosos, presididos por los obispos de Cartagena, Tortosa, Vic y Seo de Urgell, y estaban también algunos laicos partidarios del alzamiento. Pero la alocución resultó bastante distinta de la que los más fanáticos esperaban. Pío XI, que era buen orador, solía improvisar sus discursos, sin papeles, pero aquella vez, dada la importancia del caso, no sólo lo leyó en italiano sino que se había preparado un folleto con la traducción al español, que fue distribuido entre los asistentes.

El discurso La vostra presenza $a^{5}$ empezó con unos sentidos párrafos de lamentación por las víctimas de la violencia en la zona republicana y de condena del comunismo. Saludó a los prófugos diciéndoles, con palabras del Apocalipsis, que eran los venidos de "la gran tribulación" (Ap 7,14). Se refirió al "esplendor de virtudes cristianas y sacerdotales, de heroísmos y de martirios; verdaderos martirios en todo el sagrado y glorioso significado de la palabra” (era el día de la fiesta

\footnotetext{
${ }^{4}$ Raguer, Hilari (ed.), Arxiu de l'Església Catalana durant la Guerra Civil, vol. I, 1 (Montserrat, Publicacions de l'Abadia de Montserrat, 2003), págs. 76-80. Cfr. Muntanyola, R., Vidal i Barraquer, cardenal de la pau (nueva edición revisada por Massot i Muntaner, J. (Montserrat, Publicacions de l'Abadia de Montserrat, 1976), pág. 424.

5 Texto oficial original en italiano en Acta Apostolicae Sedis 28 (1936), págs. 373-381.
} 
de la Exaltación de la Santa Cruz). Pero en vez de sacar de esta memoria de las víctimas la consecuencia, por tantos esperada, de la identificación de la Iglesia con los insurrectos, como estaban ya proclamando algunos obispos y generales, Pío XI expresó acto seguido su horror por aquella guerra fratricida: "la guerra civil, la guerra entre los hijos del mismo pueblo, de la misma madre patria". Con una cita de Manzoni, añadió: "Bien se ha dicho que la sangre de un solo hombre ya es demasiado para todos los siglos y para toda la tierra; ${ }^{6}$ ¿qué decir en presencia de las matanzas fraternas que todavía se anuncian?”. Por si fuera poco, hacia el final de su alocución el Papa dijo las siguientes cautelosas palabras, que entrañaban un fuerte interrogante sobre la causa de los sublevados:

"Por encima de toda consideración política y mundana, Nuestra bendición se dirige de modo especial a cuantos han asumido la difícil y peligrosa misión de defender y restaurar los derechos y el honor de Dios y de la religión, que es tanto como decir los derechos y la dignidad de las conciencias, condición primera y base la más sólida de todo bienestar humano y civil. Misión, decíamos, difícil y peligrosa, también porque muy fácilmente el esfuerzo y la dificultad de la defensa la hacen excesiva y no plenamente justificable, además de que no menos fácilmente intereses no rectos e intenciones egoísticas o de partido se introducen para enturbiar y alterar toda la moralidad de la acción y toda la responsabilidad."

El último párrafo del discurso, referente a los enemigos de la Iglesia, parece un eco de la carta de Vidal y Barraquer:

“¿Y los otros? ¿Qué decir de todos estos otros, que también son y serán siempre hijos Nuestros? [...]. Tenemos, queridos hijos, divinos ejemplos y divinos preceptos para Nosotros y también para vosotros, que pueden parecer de demasiada difícil obediencia e imitación a la pobre y sola naturaleza humana, pero que son tan bellos y atrayentes para el alma cristiana -para vuestras almas, amadísimos hijos-, con la divina gracia, que nunca hemos podido ni podemos dudar ni un instante sobre lo que nos toca hacer a Nosotros y a vosotros: amar a estos queridos hijos y hermanos vuestros, amarlos con un amor particular hecho de compasión y de misericordia, amarlos y, no pudiendo hacer otra cosa, rezar por ellos."”

En la zona llamada nacional el discurso de Pío XI fue divulgado ampliamente, pero sólo los párrafos que parecían ratificar la condición de cruzada, suprimiendo la segunda parte y subrayando, en la primera, las frases que más les interesaban. Entre el episcopado español, que hasta entonces había guardado en general una actitud reservada, la palabra del Papa, conocida según esta versión mutilada, desató una cascada de cartas pastorales a favor de Franco y su supuesta "cruzada".

Un caso especialmente interesante es el del obispo de Salamanca, Enrique Pla y Deniel. Al recibir de la propaganda de los militares la versión mutilada, la publicó tal cual en su Boletín Eclesiástico, con este titular: "Importantísima alocución de Su Santidad sobre los sucesos de España". ${ }^{8}$ En este mismo Boletín publicó su pastoral Las dos ciudades, fechada el 30 de setiembre pero sin duda preparada de antemano, verdaderamente la más importante, teológica y políticamente, de todas las cartas pastorales sobre la guerra civil. Aplicaba a la guerra en curso toda la carga apocalíptica de De civitate Dei de san Agustín: la ciudad de Dios era la España de los insurrectos, y la republicana era la del diablo. Cuando al poco tiempo le llegó un ejemplar del texto pontificio completo, lo hizo publicar en el número siguiente del Boletín, con esta advertencia: "Faltan

\footnotetext{
${ }^{6}$ Manzoni, A., Osservazioni sulla morale cattolica, cap. VII, post initium (nota del documento vaticano original).

7 Acta Apostolicae Sedis 28 (1936), págs. 337-381.

8 B.O.E. de Salamanca, 1936, núm. 10 (30 septiembre), págs. 318-320.
} 
párrafos del discurso en el texto publicado por la mayor parte de la prensa diaria". 9 Pero con el Boletín anterior había ya publicado la carta pastoral Las dos ciudades. No se retractó nunca de ella. Parece ser que a Franco, que se había instalado en el palacio episcopal de Salamanca, le encantó aquella pastoral y adoptó su ideología como uno de los principales fundamentos del nuevo régimen.

El 23 de noviembre de 1936 Pío XI recibió en audiencia al representante de Franco, marqués de Magaz. Desde que llegó a Roma, en agosto, no había sido aún recibido, a pesar de su insistencia en pedirlo, porque salir en la lista de audiencias del Osservatore romano sería un primer paso hacia el anhelado reconocimiento diplomático. Pero Magaz no sabía que el Papa lo convocaba porque acababa de recibir un voluminoso informe del obispo de Vitoria, Mateo Múgica Urresterazu, explicando como los "cruzados" lo habían expulsado de su sede y, sobre todo, informándole de que catorce sacerdotes vascos de su diócesis habían sido fusilados y muchos más encarcelados o desterrados ${ }^{10}$. Pío XI le dijo: "En la España nacional se fusilan los sacerdotes como en la España del otro lado". Magaz le respondió de modo tan altanero que el Papa, que padecía de asma, tuvo un ataque que casi se ahoga. La audiencia acabó muy mal y Franco envió a Magaz de embajador en Berlín y tomó por intermediario al cardenal Gomá.

\section{La Iglesia española}

\section{Los obispos deseaban un golpe...}

Los obispos españoles, como en general la gente de derechas, ante el deterioro de la situación en los últimos tiempos de la República, sobre todo después del triunfo del Frente Popular en las elecciones del 16 de febrero de 1936, deseaban y esperaban que el ejército interviniera para restablecer el orden público y pusiera fin a los atentados y al anticlericalismo creciente.

\section{...pero no entraron en la conspiración}

Sin embargo, ningún obispo formaba parte de la conspiración que desembocaría en la rebelión. Algún prelado, y unos cuantos sacerdotes, no sólo deseaban un golpe militar sino que lo promovían y hasta recogían fondos para sufragarlo. Así hacía algún sacerdote del entorno del obispo de Barcelona, Manuel Irurita, integrista. Había numerosos conciliábulos que planeaban insurrección, pero los únicos que podían emprenderla con probabilidades de éxito eran los de la conspiración que organizaba desde Pamplona el general Mola, que contaba con el ejército de África, las únicas tropas profesionales disciplinadas y bien armadas. Esta conspiración, tal como se planeaba, no era monárquica ni de carácter religioso. No sería contra la República sino contra el gobierno del Frente Popular. Los generales que la integraban, como Sanjurjo, Mola, Queipo de Llano y el mismo Franco (el Franco de 1936) no se distinguían por su religiosidad, y algunos eran masones, como Cabanellas y Aranda. Todos se sublevaron con un "Viva la República". El clero belicoso no entraba en esta conspiración; la suya era otra. En los primeros tiempos de la revolución, el obispo Irurita estaba escondido en una casa de Barcelona y a una persona que fue visitarle y prestarle ayuda económica le dijo: "No os fieis de Franco; viene de Canarias, y allí todos son masones". La insurrección que el obispo Irurita deseaba no era aquella, sino otra, de extrema derecha ultracatólica.

\footnotetext{
9 B.O.E. de Salamanca, 1936, núm. 11 (31 de octubre), págs. 337-347.

10 Estos catorce son los fusilados en octubre de 1936. Posteriormente fueron fusilados dos más. El número varía según los historiadores. Véase la lista más completa y fiable en Eu₹ko Apaiz Talde [colectivo del clero vasco], Archivos del Clero Vasco, I, Año 1936... En la guerra, edición de los autores, s.l., 1978.
} 
Pero en muy poco tiempo la rebelión militar cambió de sentido, con una sobrecarga religiosa que inicialmente no tenía, hasta proclamarse guerra santa, cruzada, y ser reconocida como tal por la casi totalidad del episcopado español (pero no por la Santa Sede: ningún Papa, ni entonces ni más tarde, ha dado nunca a la guerra de España el calificativo de cruzada). Esta sobrecarga religiosa se debió sobre todo a la feroz persecución religiosa que, como reacción al alzamiento militar, y ante la impotencia de las autoridades republicanas, se desencadenó en todos los sitios donde el golpe fracasó.

\section{Adhesión “a posteriori”}

Desde el principio todos los obispos de la zona donde al alzamiento había triunfado, se adhirieron de corazón a él y lo ayudaron de varias maneras, pero discretamente, en espera de que el Vaticano se pronunciara. Salvo algún caso especial, como el de Pamplona, donde la posición prorepublicana de los nacionalistas católicos vascos exigía una toma de posición inequívoca, y el de Mallorca, donde el desembarco de una expedición militar catalana obligó al obispo a condenarla, los prelados guardaron en general prudente silencio hasta después del discurso de Castelgandolfo, conocido sobre todo en la versión mutilada. Entonces se desataron sus plumas en un alud de documentos, que generalmente declaraban cruzada aquella guerra.

\section{La carta colectiva}

La posición del episcopado español quedó sobre todo plasmada en su carta colectiva, redactada por el cardenal Gomá a petición de Franco, quejoso de las críticas del sector progresista del catolicismo internacional. Contra lo que suelen decir muchos que la alaban o la critican sin haberla leído, la carta colectiva no declara que la guerra civil sea una "cruzada", sino que expresamente dice que no lo es:

"Siendo la guerra uno de los azotes más tremendos de la humanidad, es a veces el remedio heroico, único, para centrar las cosas en el quicio de la justicia y volverlas al reinado de la paz. Por esto la Iglesia, aun siendo hija del Príncipe de la paz, bendice los emblemas de la guerra, ha fundado órdenes militares y ha organizado cruzadas contra los enemigos de la fe. No es éste nuestro caso. La Iglesia no ha querido esta guerra ni la buscó."

Gomá, Pla y Deniel y otros obispos, en cartas pastorales anteriores y en discursos o sermones, habían afirmado el carácter de guerra religiosa y de "cruzada" que según ellos tenía la contienda, pero en la carta colectiva Gomá no creyó oportuno darle esta denominación, porque deseaba que fuera aprobada por la Santa Sede y conocía la reticencia de ésta. No dice que sea una cruzada, pero la califica de "plebiscito armado", porque todos los buenos españoles se han sumado a los militares insurrectos. O sea que aprueba la gran violencia que fue la rebelión, que desembocó en sangrienta guerra civil. Pero lo que más toca a nuestro tema es la absolución que la carta colectiva imparte a la represión franquista:

"Toda guerra tiene sus excesos; los habrá tenido, sin duda, el movimiento nacional; nadie se defiende con total serenidad de las locas arremetidas de un enemigo sin entrañas. Reprobando en nombre de la justicia y de la caridad cristiana todo exceso que se hubiese cometido, por error o por gente subalterna y que metódicamente ha abultado la información extranjera, decimos que el juicio que rectificamos no responde a la verdad, y afirmamos que va una distancia enorme, infranqueable, entre los principios de justicia de su administración y de la forma de aplicarla de una y otra parte." 
El obispo vasco de Vitoria, Mateo Múgica, no opinaba así. En una carta a la Santa Sede, en junio de 1937, explicando los motivos por los que se abstenía de firmar la carta colectiva, decía:

"Según el episcopado español, en la España de Franco la justicia es bien administrada, y esto no es verdad. Yo tengo nutridísimas listas de cristianos fervorosos y de sacerdotes ejemplares asesinados impunemente sin juicio y sin ninguna formalidad jurídica."11

\section{El Vaticano y la carta colectiva}

Cuando Gomá transmitió a la Santa Sede la petición de Franco, Pacelli contestó dejándolo al buen criterio del cardenal primado, pero precisando que debería consultar al episcopado. La Santa Sede no dio ninguna respuesta, ni favorable ni desfavorable, cuando Gomá le envió el borrador de la carta. El cardenal continúa escribiendo a Pacelli para darle cuenta del proceso de elaboración del documento, de la aprobación general de los obispos y de la negativa de Vidal i Barraquer y Múgica, pero en ninguna de sus cartas de estos meses hace Pacelli la menor referencia a la carta colectiva. Ni siquiera acusó recibo cuando Gomá le envió el texto definitivo. La carta colectiva se publica entrado ya agosto, y Secretaría de Estado sigue guardando silencio. La Santa Sede tardó nueve meses en acusar recibo, y lo hizo en una forma que enfureció al gobierno de Burgos.

Un dato importante de la documentación secreta vaticana ahora asequible es que a última hora Pacelli, por orden de Pío XI, pensó detener la publicación de la carta colectiva. El 5 de julio Gomá había enviado a Pacelli las pruebas de imprenta del texto definitivo y el 20 fue enviado el texto definitivo a los obispos de todo el mundo, pero no se hizo pública hasta bien entrado agosto, para asegurarse de que los obispos ya la habrían recibido. El 31 de julio, desconociendo que ya se había enviado a los obispos, Pacelli escribe a Gomá acusando recibo de las pruebas de imprenta, y le dice:

"Esta Secretaría de Estado sería del parecer que para la publicación de un documento de tanta importancia, como es la citada carta, sería deseable la unanimidad de ese Excmo. Episcopado.

"Puesto que el Emmo. Señor Vidal y Barraquer, como Vd. observa en su mencionada carta N. 88, no estima conveniente la publicación de dicho documento, y por otra parte S. E. Mons. Múgica y tal vez con él otros Obispos españoles no desean firmarlo, esta Secretaría deja a la conocida prudencia de Vuestra Eminencia ver si no sería el caso de suspender por ahora su publicación." 12

Pero esta importante carta no llegó a enviarse. No se envió, pero no se destruyó, sino que el original, no firmado, se archivó en la Secretaría de Estado, con una anotación en lápiz, a mano, encerrada en un círculo, que dice: "Sospeso". Aun no enviada, esta carta demuestra que al Vaticano no le gustaba la carta colectiva.

Los servicios de propaganda de Franco decidieron publicar un libro con las respuestas de todos los episcopados a la carta, y Gomá pidió al Papa que lo prologara. Dada la divulgación internacional que las respuestas a la carta colectiva habían tenido, incluso publicadas algunas en el diario oficioso vaticano (que no había publicado la carta colectiva), la Santa Sede pensó que no podía escaparse de decir alguna cosa. Pero se limitó a enviar el 5 de marzo de 1938 una carta del Secretario de Estado, cardenal Pacelli, al cardenal Gomá, a través del Encargado de Negocios, monseñor Antoniutti, en la que elogiaba el documento episcopal español "por los nobles

${ }^{11}$ Citado por Iturralde, Juan de, El catolicismo y la Cruzada de Franco, t. III (Toulouse, Ed. Egui-Indarra, 1965), págs. 348-349.

12 Archivo Secreto Vaticano, Affari Esteri Straordinari, IV, vol. 16 Spagna, fasc. 282, fol. 13. 
sentimientos en que está inspirado, así como el alto sentido de justicia de esos Excmos. Obispos al condenar absolutamente el mal, de cualquier parte que venga". La propaganda franquista divulgó esta carta y la publicó a modo de prólogo al libro, pero suprimiendo las últimas palabras, "...de cualquier parte que venga". El Vaticano reaccionó publicando íntegra en el Osservatore romano la carta de Pacelli. El 2 de noviembre siguiente, el embajador de Franco, Yanguas Messía, recibido en audiencia por Pacelli, presentaba once (jonce!) capítulos de queja de su gobierno contra la política del Vaticano hacia la España "nacional". El quinto era la llamada "cartaprólogo". En vez de presentar excusas por haber alterado el texto de un documento de la Santa Sede, protestaba de su tenor original. "No puedo ocultarle -dijo Yanguas al Secretario de Estado- el penoso efecto que a la opinión católica nacional hubo de producirle su carta-prólogo al libro". Yanguas la tildaba de floja, muy poco acorde con el contenido vibrante de la carta colectiva, pero sobre todo se fijaba en aquel párrafo de la condena del mal. ${ }^{13}$

\section{Una Iglesia sin misericordia}

El episcopado español, tan sensible a la persecución de su clero, no tuvo piedad de las víctimas de los terribles bombardeos de Barcelona por la aviación alemana e italiana en marzo de 1938. Mussolini había ordenado literalmente terrorizzare le retrovie rosse et specie $i$ centri urbani. ${ }^{14}$ La Santa Sede, por medio de L'Osservatore romano, los condenó públicamente como matanzas innecesarias, carentes de justificación militar, pero la Iglesia española los aprobaba. El canónigo vasco Alberto Onaindia, que se hallaba en Guernica el día del famoso bombardeo, escribió inmediatamente a Gomá una carta patética describiendo lo ocurrido y pidiéndole una intervención humanitaria. La respuesta inmisericorde de Gomá fue: "Lamento como el que más lo que ocurre en Vizcaya [...]. Pero me permito responder a su angustiosa carta con un simple consejo: que se rinda Bilbao, que hoy no tiene más solución"." ${ }^{15}$

Pla i Deniel escribía a Gomá el 31 de agosto de 1936:

"Aquí gracias al Señor en toda la diócesis no ha habido ningún incendio de iglesias, ni asesinato de sacerdotes. El Ejército domina total y completamente la provincia, con mucha ayuda personal y económica de los paisanos". ${ }^{16}$

Pero Unamuno, que en un primer momento había aplaudido el alzamiento, al conocer la terrible represión escribía:

"Aquí en Salamanca no hay guerra, sino algo peor, porque se oculta en el cinismo de una paz en estado de guerra. No hay guerra de trincheras y bayoneta calada, pero la represión que estamos sufriendo no hay forma de calificarla... Se cachea a la gente por todas partes. Los «paseos» de presos hasta los lugares de fusilamiento son constantes. Se producen desapariciones... Hay tortura, vejaciones públicas a las mujeres que van por la calle con el pelo rapado. Trabajos forzados para muchos disidentes. Aglomeración inhumana en la cárcel. Y aplicaciones diarias de la ley de fugas para justificar ciertos asesinatos [...] ¿Qué será de mi España cuando despierte de esta salvaje pesadilla?"17

\footnotetext{
13 Informe del embajador Yanguas Messía al ministro de Asuntos Exteriores, Jordana, de 2 de noviembre de 1938. Archivo Histórico del Ministerio de Asuntos Exteriores, R 3458, núm. 11.

14 Telegrama de Mussolini al general Berti, del 14 de diciembre de 1937. Archivio Storico del Ministero degli Affari Esteri, fondo U.S. (Ufficio Spagna).

15 Gomá a Onaindia, Pamplona, 5 mayo 1937. Iturralde, op. cit., pág. 357.

16 Andrés-Gallego, José-Pazos, Antón M. (eds.), Archivo Gomá. Documentos de la guerra civil (Madrid, CSIC, 2001-2010), 1-36, págs. 102-103.

17 Citado por Josep Fontana en el prólogo a Robledo, Ricardo (ed.), Esta salvaje pesadilla. Salamanca en la guerra civil española (Barcelona, Crítica, 2007), pág. XI.
} 
En Andalucía o Extremadura en los primeros momentos los anarquistas y otros extremistas habían asesinado, y a veces torturado, a terratenientes, capataces, sacerdotes y gente de derechas. Cuando llega el ejército de África se toma la venganza multiplicada. Pero en Salamanca, o en Mallorca, no había habido disturbios ni asesinatos previos y sin embargo la represión fue durísima, ante el silencio de la jerarquía.

\section{Oposición a la paz negociada}

Hay dos grandes formas de violencia en la guerra civil: la de los frentes de batallas y la de las retaguardias. Nos ocupamos principalmente de esta última porque es la más odiosa, pero la primera es la más cuantiosa: los muertos en combate fueron muchos más que los ejecutados o asesinados en las retaguardias. Por eso es gravísima la responsabilidad de Franco, de haber alargado intencionadamente aquella guerra tan sangrienta, que podía haber terminado victoriosamente mucho antes ${ }^{18}$ y también la de los obispos españoles, que se sumaron con entusiasmo a la propaganda de Franco de que la paz solo podía venir de la victoria total, con una rendición incondicional.

Entrado ya 1938, cuando la guerra se hace más sangrienta que nunca por la batalla del Ebro y los bombardeos, algunos hombres de la llamada "tercera España", o sea los que estaban en el extranjero porque no cabían en ninguna de las otras dos, ${ }^{19}$ emprenden una campaña a favor de una intervención internacional que ponga fin a la contienda con una paz negociada. Es sobre todo el Comité por la Paz de París, organizado por Jacques Maritain, Alfredo Mendizábal y Joan Baptista Roca Caball. Paralelamente, el cardenal Vidal i Barraquer, desde su exilio, escribe a Franco, a Negrín y a los principales jefes de gobierno europeos con la misma intención. El Vaticano, sea por convicción humanitaria o porque no se pueda decir que está al margen de este propósito de paz, lo alienta de modo indirecto y discreto. El proyecto afecta de lleno a nuestro tema porque estos pacifistas (Vidal i Barraquer lo alega expresamente en sus cartas a Secretaría de Estado) piensan que si Franco alcanza una victoria total, sin ningún freno internacional, son de temer represalias masivas, especialmente en Cataluña (que es lo que sucedió). Esta campaña enfureció a Franco, porque lo que él quería era una victoria total que le diera el poder absoluto, y era precisamente por esto que estaba alargando artificialmente la guerra. Entonces Franco, tal como había hecho un año antes con la carta colectiva, recabó, también en este asunto, el apoyo de los obispos, que se lanzaron en masa a una campaña de escritos y declaraciones condenando los esfuerzos de paz. La propaganda franquista recogió todas estas declaraciones episcopales belicistas y las divulgó profusamente.

\section{E1 cardenal Gomá en Budapest}

El colmo de la campaña episcopal contra la paz fue la intervención del cardenal Gomá en el Congreso Eucarístico Internacional de Budapest, celebrado a fines de mayo de 1938. Regía entonces Hungría el almirante Miklos Horthy, que había montado una dictadura fascista caracterizada por un feroz anticomunismo y también por el antisemitismo, que le llevaría, durante la Segunda Guerra Mundial, a aliarse con Hitler y declarar en 1941 la guerra a la Unión Soviética. Fácilmente se comprende la cordialidad con que recibió a la misión española. Gomá se hospedó en el Palacio Real. No eran simples peregrinos o devotos de la Eucaristía: era una misión política,

\footnotetext{
${ }_{18}$ Me remito a Raguer, Hilari, Franco alargó deliberadamente la guerra, en Historia 16, núm. 170, junio 1990, págs. 12-19.

${ }^{19}$ Véase Preston, Paul, Las tres Españas del 36, Barcelona, Plaza \& Janés, 1998.
} 
presidida por el cardenal Gomá “en representación del Gobierno Español”, 20 acompañado del Director General de Asuntos Eclesiásticos, Mariano Puigdollers y otras personalidades franquistas, entre las que destacaría el general Moscardó, el "héroe del Alcázar", pero "las operaciones militares no consintieron al famoso general hacer el viaje proyectado". Más que de la Eucaristía, Gomá habló de España y de la guerra santa que se libraba contra el comunismo, repitiendo una y otra vez que no había más posibilidad de paz que el triunfo total de Franco.

Los que trabajaban por la paz fueron entonces tachados desde la España franquista de traidores a la patria y apóstatas de la Iglesia, pero el tiempo les ha dado la razón. Hasta un cardenal Vidal i Barraquer, que en sus informes a la Santa Sede se mostraba deseoso de la victoria de los insurrectos y opinaba que cualquier proyecto de paz debería ser "a base de Franco", ante todo no creía que en una guerra civil la Iglesia debiera identificarse con uno de los dos bandos, y por eso no quiso hacer ningún acto de adhesión pública ni quiso firmar la carta colectiva, pero además pensaba que sin una intervención de las grandes potencias europeas Franco tendría las manos libres para unas represalias indiscriminadas, que es lo que realmente sucedió. Si aquella campaña por la mediación internacional hubiera prosperado, ni la represión después de la guerra hubiera podido ser tan feroz, ni por consiguiente la reconciliación sería después tan laboriosa.

\section{Los avales}

Muy grave es la colaboración de no pocos párrocos en la represión. Se esperaría que los obispos velaran para que sus sacerdotes midieran la tremenda responsabilidad de sus actos, pero es al revés. Cuando el puesto de trabajo -especialmente el de los maestros-, la libertad o incluso la vida dependían de un aval o de un certificado de ser buen católico o de adhesión al régimen, unas circulares del arzobispo de Santiago haciéndose eco del "escándalo" de algunas personas ante los certificados que algún párroco generoso ha extendido, disponen:

“Absténganse, pues, los párrocos de dar certificados de buena conducta religiosa a los afiliadas a sociedades marxistas por el tiempo que estuvieron afiliados o en concomitancia con tales sociedades que son anticristianas; y aun de los demás, tampoco expidan certificados, si éstos han de surtir efectos ante las autoridades civiles o militares, esperando ellos, los párrocos, que las mismas autoridades civiles o militares, se los pidan de palabra o por escrito; y entonces certificarán en conciencia, sin miramiento alguno, sin tender a consideraciones humanas de ninguna clase." ${ }^{21}$

Algunos obispos hicieron suyas las circulares del de Santiago. El de Lugo va más allá y ordena que las certificaciones "se referirán siempre a determinado tiempo", porque dice que hay personas que cumplieron en tiempo de la monarquía, pero que durante la república dejaron de hacerlo, "o que en los últimos años no recibieron los sacramentos, ni ayudaron al sostenimiento del culto y clero, y desde hace algunos meses se comportan como si fueran católicos fervorosos". ${ }^{22}$ Estos no pueden ser avalados.

\section{Excepciones}

\footnotetext{
${ }^{20}$ Esta expresión, y las informaciones que siguen, se toman de las introducciones de Constantino Bayle, S.I., a la recopilación de los escritos de guerra del cardenal Gomá, Por Dios y por España, Barcelona, Casulleras, 1940, págs. 489-520, contrastadas con la información publicada en La Paix Civile, mayo-junio de 1938.

${ }^{21}$ Cit. por Álvarez Bolado, A., "Guerra civil y universo religioso. Fenomenología de una implicación” (I), en Miscelánea Comillas 44 (1986), págs. 233-300.

${ }^{22}$ Ibid., pág. 298.
} 
Una encomiable excepción es la de Fray Gumersindo de Estella. ${ }^{23}$ En sus patéticas memorias refiere la gran cantidad de personas fusiladas tras un simulacro de juicio. La mayoría no habían visto al oficial asignado defensor de oficio hasta el día del consejo de guerra. Algunos le hablaban de las pruebas que tenían de su inocencia, pero que no habían tenido ocasión de aportar. Muchos eran víctimas de rastreras venganzas privadas. Eran constantes los insultos que les dirigían los capellanes de prisión en los sermones que obligatoriamente tenían que escuchar. Fray Gumersindo no los podía salvar, pero los trataba con respeto y compasión, lo cual era ya un gran alivio.

\section{Entierros con fusilamientos}

Como una rara y casi única excepción en el campo del episcopado español, conviene destacar la actuación del obispo de Pamplona, Marcelino Olaechea Loizaga y su alocución del 15 de noviembre de 1936 condenando la práctica, demasiado repetida, de ciertas ejecuciones que eran más bien linchamientos. Cuando en el frente había muerto un mozo y lo llevaban a su pueblo para enterrarlo, a menudo la ceremonia terminaba con la ejecución expeditiva, sin trámite judicial alguno, de algunos rojillos de la localidad. La práctica se había extendido tanto en la catolicísima Navarra que Olaechea se creyó en el deber de condenarla públicamente, aprovechando un acto de imposición de las insignias de Acción Católica a unas señoras:

“[...] iPerdón, perdón! ¡Sacrosanta ley del perdón!

“iNo más sangre, no más sangre! No más sangre que la que quiere el Señor que se vierta, intercesora, en los campos de batalla, para salvar a nuestra Patria gloriosa y desgarrada; sangre de redención que se junta, por la misericordia de Dios, a la sangre de Jesucristo, para sellar con sello de vida, pujante y vigorosa, a la nueva España, que nace con tantos dolores."

Más adelante el prelado, poniendo todo su talento oratorio al servicio de su mensaje humanitario, describe crudamente en qué consistía aquella costumbre que se estaba repitiendo en los entierros:

“¡Católicos! Cuando llegue al pueblo el cadáver de un héroe muerto por defender a Dios y a la Patria en el frente de batalla, y lo lleven en hombros y llorando los mozos, sus compañeros de valentía, y una turba de deudos y amigos acompañe sollozando el féretro, y se sienta hervir la sangre de las venas y rugir la pasión en el pecho y descerraje los labios un grito de venganza... entonces que haya un hombre, que haya una mujer que pague, sí, a la naturaleza su tributo de lágrimas (si no las puede sorber el corazón), pero que se llegue al ataúd, extienda sobre él los brazos y diga con toda su fuerza: «No, no; atrás; la sangre de mi hijo es sangre redentora; estoy oyendo su voz, como la de Jesucristo en la Cruz; acercaos y sentiréis que dice: ¡Perdón! ¡Que a nadie se le toque por mi hijo! ¡Que nadie sufra! ¡Que se perdone a todos! Si el alma bendecida de mi mártir, que goza de Dios, se os hiciera visible, os desconocería. Si os dierais a la venganza y os pudiera maldecir, os maldeciría yo y mi hijo»."

En los pueblos todo el mundo se conocía y se sabía por quién votaba cada cual. Podemos imaginar la angustia de los que eran conocidos como de izquierdas cuando se anunciaba el entierro de un voluntario.

En aquel clima, el mero hecho de que antes de estallar el conflicto alguien no acostumbrara a ir a misa o no practicara los sacramentos podía ser mortal. Olaechea, además de condenar

\footnotetext{
${ }_{23}$ Gumersindo de Estella, Fusilados en Zaragoza, 1936-1939: tres años de asistencia espiritual a los reos, Zaragoza, Mira,
} 2003. 
patéticamente aquellos linchamientos, afronta el problema pastoral del terror imperante y dicta la única actitud admisible entre los que se tienen por cristianos:

"Yo veo levantarse en cada pueblo una montaña gigantesca de heroísmo, y un alma insondable de angustias y temores. De temores. Almas que vienen en tropel y temblorosas a la Iglesia en busca del bautismo y matrimonio, confesión y eucaristía. Vienen con sinceridad; pero no venían antes. Se han roto los eslabones de las cadenas que las aprisionaban y corren al caliente consuelo de la fe. Pero traen el miedo, atravesado como una daga, en el alma. Y los hemos de ganar con la sinceridad de nuestra fe, con la sinceridad de nuestro cariño, con la justicia social y la caridad." 24

Olaechea hizo que este documento apareciera, además del Boletín Eclesiástico, en la prensa local. Ordenó también que los párrocos lo leyeran en la misa solemne del primer día festivo y que, además, lo comentaran debidamente, "dentro del espíritu que lo informa." 25

\section{Las "Normas" del P. Huidobro"}

El P. Fernando Huidobro era un jesuita santanderino que estudiaba filosofía en Alemania, discípulo predilecto de Heidegger. Sentía vivamente el espíritu de cruzada y quiso incorporarse al ejército rebelde como capellán en Navarra, pero allí sobraban curas. Fue a Talavera de la Reina, donde se unió como capellán de la Legión a la columna de Castejón, con la que avanzó hasta las puertas de Madrid. En aquella marcha fue testigo de las matanzas de la "columna de la muerte". ${ }^{27}$ Viniendo de un entusiasta del alzamiento como él, sus protestas adquieren un valor irrefutable. Redactó dos escritos, dirigido uno a las Autoridades Militares y otro al Cuerpo Jurídico Militar, titulados Sobre la aplicación de la pena de muerte en las actuales circunstancias. Normas de conciencia. Se proponía, según dice, "formar la conciencia de los Jefes y Oficiales del Ejército, y evitar que en el uso de facultades extraordinarias de justicia, que ahora por fuerza de las circunstancias tienen que desempeñar, haya excesos que manchen el honor de nuestras armas". Dejemos ahora la cuestión moral de si las "circunstancias" por él aludidas justificaban un alzamiento militar, en contra de la doctrina de la Iglesia de la obediencia a la autoridad legítima, y de quién era el P. Huidobro para decirles a los militares en qué casos podían matar. Fijémonos sólo en las prácticas usuales de la columna Castejón de las que él es testigo cuando dicta cómo han de moderarlas.

En el primer escrito, dirigido a las autoridades militares, dice:

"Toda condenación en globo, sin discernir si hay inocentes o no en el montón de prisioneros, es hacer asesinatos, no actos de justicia. [...] El rematar al que arroja las armas o se rinde, es siempre un acto criminal [...]. Los excesos que personas subalternas hayan podido ejecutar, están en contradicción manifiesta con las decisiones del Alto Mando, que ha declarado muchas veces querer el castigo de los dirigentes, y reservar a las masas seducidas para un juicio posterior, en que habrá lugar a la gracia [...]."

En el segundo escrito, dirigido al Cuerpo Jurídico Militar, se decía:

\footnotetext{
${ }^{24}$ BOE de Pamplona, 12 diciembre 1936, págs. 429-431.

25 Ibid.

26 Véase Peiró, Francisco X., S.J., Fernando Huidobro, jesuita y legionario, Madrid, Espasa-Calpe, 1951; Valdés, Rafael, S.J., Fernando Huidobro, intelectual y héroe, Madrid, Apostolado de la Prensa, 1966; Sanz de Diego, Rafael Ma , S.J., "Actitud del P. Huidobro ante la ejecución de prisioneros en la guerra civil. Nuevos datos”, en Estudios Eclesiásticos, 60, núm. 235 (octubre-diciembre 1985), págs. 443-484 (edita íntegros doce documentos de Huidobro sobre este tema, con una excelente introducción).

27 Véase Espinosa Maestre, Francisco, La columna de la muerte. El avance del ejército franquista de Sevilla a Badajoz, Barcelona, Crítica, 2003.
} 
"Se puede afirmar que los asesinos de mujeres, sacerdotes y otras personas innocuas; los autores de esos crímenes repugnantes que marcan un grado infrahumano de perversión en la naturaleza, con casos de un sadismo asqueroso; los que han incurrido en delitos que todo Código sanciona con penas gravísimas, pueden merecer la pena de muerte. Y si no son locos o idiotas se presume que la merecen. Lo mismo se puede decir de los guías y promotores conscientes de un movimiento como el comunista, que lleva en sí tales horrores; los que desde el periódico, el libro o el folleto han excitado a las masas [...]. En cambio hay que proceder con suma lenitud cuando se trata de las masas engañadas [...]. No se incurre en la responsabilidad necesaria para merecer la pena de muerte por el mero hecho de estar afiliado a la CNT o a la UGT; ni aún por tomar un fusil para defender ideales, equivocados, pero sinceramente tenidos por lo mejor para la sociedad."

El P. Huidobro envió sus Normas a numerosas autoridades militares y a muchos capellanes castrenses. Parece ser que recibió muchas alabanzas, si bien algunos moralistas las encontraron demasiado rígidas, atendidas las circunstancias (o sea, que pensaban que ponía demasiados límites a las ejecuciones). Dice su biógrafo que "algunas excepciones que encontró, de no aceptar en su integridad las Normas, le fueron al Padre Huidobro de amargo dolor". Consta que las leyeron Castejón y hasta Varela. A este último general el P. Huidobro le escribió, el 14 de noviembre, cuando avanzaba rápidamente hacia Madrid, rogándole que, ya que estaba destinado a ser el conquistador de España, no permitiera que sobre su glorioso nombre recayera la mancha de los asesinatos que algunos de sus subordinados clamaban que harían, para escarmiento. El 3 de diciembre le contestó Varela, desde Juncos, felicitándole por los sentimientos que demostraba y asegurándole que coincidía con su criterio. Apuntando al vértice, el P. Huidobro se atrevió a enviar al mismísimo Franco, por conducto de su ayudante, el teniente coronel Carlos Díaz Varela, sus Normas, a las que añadió un escrito denunciando excesos concretos cometidos. Díaz Varela estimó que el Generalísimo estaba demasiado atareado para atender a semejantes minucias, pero envió aquellos escritos al general Yagüe, que mandaba la división en la que estaba encuadrada la $4^{a}$ Bandera de la Legión, la unidad de Huidobro. Pero éste insistió y Díaz Varela le contestó que había pasado sus escritos al Generalísimo, quien, al conocer los abusos cometidos, "se indignó" y "lamentó que no le avisasen a él en seguida estas cosas". El 25 de noviembre Díaz Varela escribía desde Salamanca al P. Huidobro:

"Pude enterar de sus quejas a la persona que deseaba. Las encontró justificadísimas y condenó, como se merecen, los excesos que denuncia. Enemigo sincero de ellos, le aseguro que sólo desea que puedan ser señalados sus autores o inductores, para ser sancionados con el rigor que merecen. Son muy lamentables esas extralimitaciones de algunos locos, que sólo sirven para desprestigiar la causa y ofender seriamente a Dios."

El error del P. Huidobro estribaba en creer que las matanzas que presenciaba las ejecutaban unos "locos", contra las consignas de los buenos y cristianos generales, cuando en realidad eran unos legionarios muy disciplinados que cumplían fríamente las instrucciones recibidas, programadas de antemano por el "Director" del Movimiento, el general Mola y asumidas por Franco, Varela, Yagüe, Castejón y todos los jefes de las columnas. Pero les convenía a aquellos generales no escandalizar a un sacerdote que los secundaba tan ardorosamente.

El padre Hidobro murió en el frente de Madrid, donde había ido a ejercer su ministerio en primera línea, hasta que una granada le destrozó la cabeza. Se había iniciado el proceso de beatificación del P. Huidobro, como mártir, pero sus promotores lo suspendieron al descubrir que la granada que lo mató no procedía de los rojos, sino de "fuego amigo". De modo que, si lo matan casualmente los rojos, es un mártir, pero si lo asesina alguien de la Legión porque denunciaba sus fusilamientos, ya no se le puede canonizar. 


\begin{abstract}
Aita Patxi ${ }^{28}$
Aita Patxi (en euskera, "Padre Francisco") es el Maximiliano Kolbe del clero vasco, pero lo suyo aconteció dos veces y tres o cuatro años antes de la muerte de aquel santo polaco. En la guerra civil fue capellán de un batallón de gudaris, los soldados del ejército nacionalista vasco, y cayó preso al final de la campaña de Vizcaya, en junio de 1937. Estaba preso en Guernica durante el famoso bombardeo, inmortalizado por Picasso.
\end{abstract}

Ocurrió un día que un preso asturiano, al parecer comunista, intentó escaparse, pero fue atrapado y condenado sumarísimamente a muerte. Aunque aquel infeliz no era creyente, Aita Patxi quiso al menos acompañarlo en su última noche, antes de que al amanecer lo fusilaran. Pero mientras pasaba con él la noche, y al hablarle el condenado de su familia, se le ocurrió que podía hacer algo más eficaz que acompañarlo hasta el paredón. Aita Patxi se dirigió al comandante del campo y le pidió, como una gracia, que le permitiera sustituir al que iba a ser fusilado. El comandante, según han atestiguado los gudaris presos, era hombre brusco, pero en el fondo de buenos sentimientos. Quedó estupefacto ante la propuesta y dijo que tenía que consultarlo con sus superiores, pues no se atrevía a fusilar a un sacerdote. De momento suspendió la ejecución. Pero ya fuera por iniciativa suya o por orden de más arriba, quiso comprobar que el ofrecimiento de Aita Patxi no era un farol, sino que realmente estaba dispuesto a llegar hasta el final. A las diez de la noche envió al barracón dormitorio donde estaba el religioso un piquete de cuatro soldados con casco y fusil con la bayoneta calada, que tomaron consigo a Aita Patxi y lo condujeron a la comandancia. Aita Patxi sólo había contado a uno de sus compañeros la petición formulada. Se despidió de todos serenamente con un izerurarte! (“'hasta el cielo!”). Llegado al puesto de mando, el comandante le comunicó que el gobierno aceptaba la sustitución pedida. Aita Patxi le dio las gracias, se recogió unos momentos en profunda oración y dijo: "Ya estoy a punto". Lo condujeron al lugar destinado a las ejecuciones y ante él formó el pelotón de ejecución. Tenemos sobre este momento dramático los testimonios coincidentes de dos testigos, uno de los cuales refiere lo que el propio comandante le contó más tarde en el campo de concentración de Miranda de Ebro, al que había sido trasladado. Dicen, pues, los dos testigos que mientras Aita Patxi rezaba el rosario sonriendo de felicidad por la vida que salvaba, los demás presentes lloraban, hasta que el comandante cortó la escena gritando: “'Retírese, Padre!” Le notificó entonces que el gobierno, en atención a su intervención, había perdonado la vida al asturiano que había intentado fugarse. Aita Patxi se fue a dormir muy contento, pero al día siguiente se enteró con gran pena de que aquella misma madrugada habían fusilado al hombre por quien había querido dar la vida.

El caso se repitió más adelante. Los presos procedentes del Norte habían sido incorporados a batallones de trabajo y tenían que cavar trincheras y minas en el frente de Madrid. Se había hecho pública la orden de que si alguno de los presos se pasaba a los republicanos, serían fusilados algunos de sus compañeros de unidad o dormitorio. Alguien se pasó, y cinco de aquellos presos del mismo batallón de trabajo, sorteados arbitrariamente, fueron condenados a ser ejecutados. Cuando los sacaron de la formación y los hicieron poner en fila aparte, Aita Patxi se incorporó sin decir nada al grupo de los condenados. El teniente que mandaba la operación le ordenó que se fuera, pero Aita Patxi le contestó: "Si matan a esos pobres sin ningún juicio, que me maten también a mí". Hubo asombro general, vacilación, consultas y finalmente aquella vez no se fusiló a nadie.

\footnotetext{
${ }^{28}$ Véase Raguer, Hilari, Aita Patxi. Prisionero con los gudaris, Barcelona, Claret, 2006.
} 


\section{Capellanes de prisiones}

Son incontables los testimonios de la dureza de los capellanes de prisiones y campos de concentración. Insultaban a los presos y les decían que no eran dignos de la benevolencia que les mostraba el Caudillo.

Cuando fue apresado el barco en que viajaba con su esposa y seis de sus ocho hijos el político cristiano Carrasco y Formiguera, éste fue llevado a la cárcel provincial de Burgos, su mujer con la pequeña de meses y la nodriza a la cárcel de mujeres de la misma ciudad, y los demás hijos a San Sebastián, las dos hijas mayores, de 20 y 18 años, a una cárcel de mujeres y los tres pequeños, Raimon, Josep y Neus, de 13, 11 y 9 años respectivamente, a un orfelinato convertido en cárcel para rehenes. Las religiosas que llevaban el orfanato carcelario eran crueles con los niños. La pequeña tenía que lavar grandes cantidades de ropa de las monjas. El primer domingo se disponían a comulgar, como hacían siempre cuando iban a misa con sus padres, pero no se lo permitieron porque eran rojos y antes tenían que confesarse. Se confesaron y el sacerdote les impuso la penitencia de rezar un padrenuestro por la conversión de su padre.

El capellán de la prisión de Burgos P. Bolinaga S. J., dirigía a los condenados a muerte duras palabras. Ramón de Galarza recuerda sus coacciones e insultos. ${ }^{29}$ Reprochaba a los presos sus grandes crímenes, que les llevarían irremisiblemente al infierno si no se confesaban, y elogiaba la justicia del Caudillo.

No había preocupación por la vida de los condenados, pero sí por su sacramentalización. El alférez capellán de Yagüe atestigua, según Calleja, cómo lamentaba las sentencias de muerte que se veía obligado a dictar, y cómo procuraba que las víctimas se confesaran antes de la ejecución. ${ }^{30}$

Los obispos españoles, en la antes citada carta pastoral de $1^{\circ}$ de julio de 1937 , dicen tener el consuelo de poder decir que:

"al morir, sancionados por la ley, nuestros comunistas se han reconciliado en su inmensa mayoría con el Dios de sus padres. En Mallorca han muerto impenitentes sólo un $2 \%$; en las regiones del Sur no más de un $20 \%$; y en las del norte no llegan tal vez al $10 \%$. Es una prueba del engaño de que ha sido víctima nuestro pueblo". ${ }^{31}$

El obispo Miralles, de Mallorca, se sentía muy satisfecho de poder decir: "solamente el $10 \%$ de estos amados hijos nuestros han rehusado los santos sacramentos antes de ser fusilados por nuestros buenos oficiales". ${ }^{32}$

La pastoral de los condenados a muerte es uno de los aspectos más negros de la actitud de la Iglesia española ante la represión de la guerra y la primera posguerra. En ocasiones anteriores he citado un libro publicado en 1942 por el capellán de la Cárcel Modelo de Barcelona donde decía:

"Sólo al condenado a muerte, en lo que humanamente cabe, le es posible saber la hora fijada en que ha de comparecer ante aquel juez, cuyo juicio, supremo, decisivo e inapelable, es lo único que puede para toda una eternidad interesarle. ¿Cuándo moriré? ¡Oh, si lo supiera!, repiten a diario las voces íntimas de millones y millones de conciencias. Pues bien: el único hombre que tiene la incomparable fortuna de poder contestar a esa pregunta es el condenado a muerte. «Moriré a las cinco de esta misma mañana.» ¿Puede darse una gracia mayor para un alma que haya andado en su vida apartada de Dios?"33

\footnotetext{
29 Galarza, Ramón de, Diario de un gudari condenado a muerte, Ediciones Vascas, San Sebastián 1977.

${ }^{30}$ Calleja, J. J., Yagüe, un corazón al rojo (Juventud, Barcelona, 1963), págs. 179-180.

31 Carta colectiva, $\mathrm{n}^{\circ} 6$.

32 Palabras recogidas por Thomas, Hugh, La guerra civil española, pág. 186, que cita Bernanos, Les grands cimetières sous la lune, pág. 69 (pág. 74 de la edición de 1938 aquí citada).

33 Torrent, Martín Pbro., Capellán de la Prisión Celular de Barcelona, ¿Qué me dice usted de los presos?, Alcalá de Henares, Imp. Talleres Penitenciarios, 1942, pág. 68.
} 
Me estremecía la cínica inconsciencia de este capellán de prisiones, hasta que supe que estas palabras, y el libro entero, no eran obra suya, sino que, como ha demostrado Vicent Comes, son de un político cristiano preso y condenado a muerte: Luis Lucia y Lucia. ${ }^{34}$

En la revista sacerdotal de la Compañía de Jesús Sal Terrae, en el número de enero de 1938, se publicó un dictamen sobre la administración de la extremaunción que mereció ser reproducido por el Boletín Oficial del Arzobispado de Toledo del 15 de marzo. Era su autor uno de los más famosos, si no el más famoso, entre los moralistas-canonistas españoles de entonces, el P. Eduardo Fernández Regatillo, S. J. En el acreditado consultorio práctico de aquella revista sacerdotal respondía a la siguiente cuestión: "¿Se puede y se debe dar la extremaunción a los condenados a muerte?" La respuesta era:

"Es cuestión de suma actualidad, pues por cientos se cuentan los condenados a la máxima pena por los tribunales militares; y son ajusticiados comúnmente por fusilamiento; y los reos de más graves y numerosos crímenes por la horca o garrote".

A pesar del elevado número de ejecuciones, la cuestión que el P. Regatillo se planteaba no era la moralidad de tantos fusilamientos, sino si en tales casos el sacramento de la extremaunción era lícito, o al menos válido. El docto teólogo examinaba el parecer de varios autores, para, por su parte, terminar opinando que la extremaunción ${ }^{35}$ era un sacramento destinado a enfermos a punto de morir. El condenado a quien van a fusilar no está necesariamente enfermo, pero ciertamente está a punto de morir. El caso era dudoso, pero teniendo en cuenta que en materia de sacramentos hay que ser amplio, se sentía generoso y concluía que lo mejor sería administrar el sacramento, aunque por la duda se hiciera sub conditione. Terminaba con un pequeño detalle de rúbricas ceremoniales: el momento más oportuno para la extremaunción del reo sería "después de la primera descarga, antes del tiro de gracia".

El P. José Agustín Pérez del Pulgar, S. J., se enorgullecía de haber creado la "Redención de penas por el trabajo", en colaboración con el director general de Prisiones, que curiosamente se llamaba Máximo Cuervo. Trabajando en la cárcel (o en el Valle de los Caídos, o en las marismas del Guadalquivir) se les descontaban a los presos días de pena y además ganaban unos jornales, que podían enviar a su familia. El gran negocio lo hacían las empresas que se lucraban con el trabajo de los presos pagando unos jornales miserables. Pero en esta "redención", que se pretendía muy humana y cristiana, subyace la concepción perversa de que aquellos presos no eran solo delincuentes, sino también pecadores, por ser rojos, y por eso necesitaban expiar con el trabajo; como Adán y Eva después del pecado original.

\section{Conclusión: La Iglesia de España ha de pedir perdón}

Los representantes de la jerarquía eclesiástica española han soslayado con demasiada ligereza la sugerencia de pedir públicamente perdón por su responsabilidad histórica en la guerra civil y en el franquismo, tal como ha hecho la Iglesia de Argentina y la de Chile. Las declaraciones de algún prelado español parecen decir: "¿Y a mí, qué me cuenta usted? Yo no hice nada de lo que ahora nos reprochan". Si los representantes de algunos estados, más allá de los cambios políticos, nos dan ejemplo al pedir perdón a los pueblos a los que causaron graves daños, la Iglesia, y las Iglesias, deberían hacerlo con mayor razón, porque, a diferencia de los estados, en la Iglesia ha

\footnotetext{
${ }^{34}$ Véase Comes Iglesia, Vicent, En el filo de la navaja: biografia política de Luis Lucia Lucia (1888-1943). Madrid, Biblioteca Nueva, 2002.

${ }^{35}$ La reforma litúrgica de después del Concilio Vaticano II, volviendo a la tradición más genuina, ha restablecido la concepción clásica de este sacramento como "unción de los enfermos", y no, como en la práctica había venido a ser, unción de los moribundos o agonizantes, que de hecho eran a veces personas ya fallecidas.
} 
habido y hay cambios de gobierno, pero nunca habrá cambio de régimen. "Aquella" Iglesia será siempre la "nuestra".

Treinta y dos años después de terminar la guerra, cuando el cardenal Enrique Vicente y Tarancón presidía la conferencia episcopal española, en la Asamblea conjunta de obispos y sacerdotes, celebrada en Madrid en septiembre de 1971 al calor del Concilio y con amplia participación y cuidadosa preparación, se planteó la necesidad de que la Iglesia pidiera pública y corporativamente perdón por la actitud adoptada en la guerra civil. Se puso a votación esta propuesta:

"«Si decimos que no hemos pecado, hacemos a Dios mentiroso y su palabra ya no está en nosotros» (1 Juan 1,10). Así, pues, reconocemos humildemente y pedimos perdón porque nosotros no supimos a su tiempo ser verdaderos «ministros de reconciliación» en el seno de nuestro pueblo, dividido por una guerra entre hermanos."

Este texto obtuvo 137 votos a favor, 3 nulos, 78 en contra, 19 “iuxta modum" y 10 en blanco. Como la mayoría favorable no llegaba a los dos tercios exigidos por el reglamento de la asamblea, se debatieron las posibles modificaciones y finalmente se sometió de nuevo a votación, añadiendo una palabra, "no siempre supimos". Pero fuera que algunos inicialmente partidarios de pedir perdón se hubieran echado atrás, o, más probablemente, porque a otros desagradó la redacción atenuada con el "siempre", obtuvo menos votos, aunque manteniendo la mayoría: 123 sí, 0 nulos, 113 no y 10 en blanco. ${ }^{36}$ Aun así, aquella votación marcó un hito histórico. La asamblea conjunta fue un gran momento de sinceridad y autocrítica de la Iglesia española, que no ha vuelto a producirse. Posteriormente, a propósito, por ejemplo, de las beatificaciones de mártires de la guerra civil, la Iglesia ha dicho que perdona, pero no ha pedido perdón.

Acabaré reproduciendo unas dramáticas palabras del ministro vasco republicano y católico Manuel de Irujo. Escribía al cardenal Vidal i Barraquer, ya hacia el final de la guerra, recordando todo lo que había hecho denunciando ante el gobierno de la República la persecución religiosa, salvando a sacerdotes, religiosos y otras personas amenazadas, sacando de la cárcel a sacerdotes que no tenían otro cargo fuera de su condición eclesiástica, ofreciendo el restablecimiento del culto público, propiciando la reconciliación de la Iglesia con la República, normalizando la vida de la Iglesia en la zona republicana, asistiendo al obispo de Teruel preso e incluso ofreciéndolo al Vaticano a condición de que permaneciera en Roma hasta el fin de la guerra. En todo esto, decía muy dolido, había fracasado, y no por culpa del gobierno, sino por la falta de cooperación de las autoridades eclesiásticas. Por eso, sintiéndose fracasado en su noble esfuerzo por ser a la vez fiel a la República y a su fe cristiana, terminaba así:

"Tenga presente que en las dos zonas se han hecho mártires; que la sangre de los mártires, en religión como en política, es siempre fecunda; que la Iglesia, sea por lo que fuere, figurará como mártir en la zona republicana y formando en el piquete de ejecución en la zona franquista." 37

\footnotetext{
36 Asamblea conjunta Obispos-Sacerdotes. Edición preparada por el Secretariado Nacional del Clero (Madrid, Biblioteca de Autores Cristianos, 1971), pág.161.

${ }^{37}$ Irujo a Vidal i Barraquer, 4 de julio de 1938. Archivo Vidal i Barraquer, parte aún inédita.
} 